Ferguson L, Learmonth D, McGregor PG, Swales JK \& Turner K (2007) The impact of the Barnett formula on the Scottish economy: endogenous population and variable formula proportions, Environment and Planning A, 39 (12), pp. 30083027.

This is the peer reviewed version of this article

NOTICE: this is the author's version of a work that was accepted for publication in Environment and Planning $A$ resulting from the publishing process, such as peer review, editing, corrections, structural formatting, and other quality control mechanisms may not be reflected in this document. Changes may have been made to this work since it was submitted for publication. Linda Ferguson, D Learmonth, Peter G McGregor, J Kim Swales, Karen Turner, 2007. The definitive, peer-reviewed and edited version of this article is published in Environment and Planning A 39(12) pp. 3008-3027, DOI: 10.1068/a38254 


\title{
The Impact of the Barnett Formula on the Scottish Economy: Endogenous Population and Variable Formula Proportions \\ March 2006
}

\author{
by \\ Linda Ferguson* \\ David Learmonth* \\ Peter G McGregor**+ \\ J Kim Swales*+ \\ and \\ Karen Turner**
}

* Fraser of Allander Institute, Department of Economics, University of Strathclyde

+ Centre for Public Policy for Regions (CPPR), Universities of Glasgow and Strathclyde

** Department of Economics, University of Strathclyde.

(Corresponding author: email p.mcgregor@ strath.ac.uk) 


\begin{abstract}
The Barnett formula is the official basis upon which increments to public funds are allocated to the devolved regions of the UK for those parts of the budget that are administered locally. There is considerable controversy surrounding the implications of its strict application for the relevant regions. The existing literature focuses primarily on the equity of the spatial changes to government per capita expenditure that would accompany such a change. In contrast, this paper attempts to quantify the system-wide economic consequences - the real, relative resource squeeze that accompanies the financial relative squeeze - on one devolved region, Scotland. The analysis uses a multi-sectoral regional computable general equilibrium modelling approach. We highlight the importance of population endogeneity, particularly since the population proportions used in the formula are now regularly up-dated.
\end{abstract}




\section{Introduction}

The Barnett formula is the official basis upon which increments to public funds are allocated to the countries of the UK - Northern Ireland, Scotland and Wales - for those parts of the budget that are administered locally. In the past, actual allocations have differed markedly from the Barnett benchmarks. However, recent moves towards devolution, and the way that Barnett features in the funding of devolved expenditures, have significantly increased the level of interest in the formula. There is considerable controversy surrounding the implications for the relevant regions of the UK.

The existing literature improves our understanding of the Barnett formula but is extremely circumscribed. It focuses primarily on the equity of the spatial changes to government per capita expenditure that would accompany the strict imposition of the formula under various scenarios. The system-wide economic consequences of its strict imposition have been neglected, despite the fact that the Barnett formula drives the regional distribution of an important element of aggregate demand. The present paper attempts to fill this gap and in particular to focus on the effects of population endogeneity, especially in the presence of the regular up-dating of the population weights that was introduced in 1997 . We use a multisectoral regional computable general equilibrium model to quantify the relative, real resource Barnett squeeze on the Scottish economy.

Section 2 presents an account of how the Barnett formula allocates the devolved budgets and the way in which the operation of the formula has changed over time. Section 3 defines the notion of a Barnett equilibrium as a distribution of public expenditure which, if reached, would be subsequently replicated through the action of the formula. In Section 4 we outline the Scottish Computable General Equilibrium model, AMOS, which is used to simulate Barnett equilibria under various assumptions concerning the specific administration of the formula and the flexibility of the regional economy. Section 5 reports and explains the simulation results, which allow us to identify the macroeconomic consequences for the Scottish economy of 
Barnett being adhered to until per capita government expenditure is equalized with England. Section 6 is a short conclusion.

\section{Devolved Budgets under Barnett}

For our purposes, it is sufficient to know that any increase (or decrease) to the assigned budgets of the devolved authorities should be determined by the Barnett formula. The assigned budget covers spending under headings such as Health, Social Work, and Education in the devolved authorities. ${ }^{1}$ In 1999 , the base year in this study, $77 \%$ of the government final demand identified in the Scottish input-output accounts is funded from the assigned budget. The remainder consists of final demands attributable to programmes reserved to the UK government or financed by local authority expenditures.

The Barnett formula allocates a population-based share of any change in comparable English DEL expenditure to the devolved authorities of the UK: it does not operate on the base. The formula implies that marginal changes in expenditures covered by the assigned budget in Scotland are determined by the difference equation:

$$
\Delta G_{S, t}=\alpha_{t} \Delta G_{E, t}
$$

where: $\mathrm{G}$ is the nominal level of expenditures covered by the assigned budget, the subscripts $\mathrm{E}$, $\mathrm{S}$ and $\mathrm{t}$ stand for England, Scotland and time period respectively, $\Delta$ is the first difference operator and $\alpha$ is a parameter based upon the ratio of Scottish to English population. However, the population weights used in the formula, that is the population numbers that determine the value of the parameter $\alpha_{t}$ in equation (1), have changed over time.

\footnotetext{
${ }^{1}$ The Assigned Budget covers most of the activities of the devolved administrations, and is the part of Departmental Expenditure Limit (DEL) that is formula-driven. Neither the balance of DEL nor Annually Managed Expenditure (AME), the other components of the total funding available to the devolved administrations, are formula-driven. More detail on the different public spending aggregates that apply to the devolved authorities is given in H M Treasury (2004) and Ferguson et al (2003).
} 
The Barnett formula was used for the first time in 1978 in Scotland and two years later for Northern Ireland and Wales, and has been in continuous use ever since. ${ }^{2}$ The population proportions used at the time of the formula's initial implementation were estimates for 1976. Under the Barnett formula Scotland then received $10 / 85^{\text {ths }}$ of any increase or decrease in comparable English programmes (HM Treasury, 2004).

There have been a number of subsequent changes to the Barnett allocation mechanism. First, up until 1985 the formula was applied in real terms with figures rolling forward from one year to another with an in-built allowance for inflation. However, post-1985 expenditure changes have been allocated in nominal terms only (HM Treasury, 2004). Second, in 1992, Michael Portillo, as Chief Secretary to the Treasury, revised the formula to reflect the population figures given in the 1991 Census, thereby reducing the value of $\alpha_{t}$ in equation (1) from $11.76 \%$ to $10.66 \%$ (McCrone, 1999). Finally in 1997 a rather more fundamental modification was introduced. Chief Secretary to the Treasury, Alastair Darling, committed the government to regular revision of the Barnett population weights at each Spending Review, based on the latest population estimates for England, Scotland and Wales, published by National Statistics (HM Treasury, 1997). This adjustment, which we henceforth refer to as the "Darling amendment", was to take effect from $1999 .^{3}$

A factor central to the debate concerning the operation of the Barnett formula in Scotland is that at present Scotland's per capita identifiable expenditure is higher than the corresponding

\footnotetext{
2 The formula was named after the then Chief Secretary of the Treasury, Joel Barnett. The formulaic approach to allocating public expenditure between the countries of the UK goes back to Chancellor Goschen in 1888 (e.g. Heald and McLeod, 2002b). He introduced a formula to allocate probate duties between countries in support of local government expenditure, based on each country's overall proportionate contribution to the Exchequer. This formula was also used as a basis for allocating some elements of public expenditure (e.g. education grants).

${ }^{3}$ The population proportions used in the 1998 Comprehensive Spending Review related to 1996 mid-year population estimates. These reported Scotland's population as 10.45\% of the English value. For the 2004 review the 2003 mid year population estimate was used (10.20\% of the English value). (HM Treasury, 2004, p10.) While the original intention was to update population estimates annually (HM Treasury, 2004, Annexe A p.38), they are now updated biennially in line with spending reviews.
} 
English figure (by $18 \%$ in 1999-2000, though this rises to $25 \%$ if Social security is excluded, Heald and McLeod, 2002a, Table 10.2). Under strict adherence to the Barnett formula, the marginal allocation of the assigned budget to Scotland is lower than its average allocation. Much of the Scottish literature surrounding the operation of the Barnett formula therefore focuses on the fact that with increasing nominal public expenditure in England, the proportionate public expenditure advantage at present enjoyed by Scots will decline. This is the so-called Barnett squeeze (see, for example, Bell et al 1996; Cuthbert, 2001; Edmonds, 2001; Heald, 1996; Heald and McLeod, 2002a; Kay, 1998; McCrone, 1999; McLean and McMillan, 2003, Midwinter, 2000, 2002; Twigger 1998.)

It is important to say that during much of the period since 1979, bypass and adjustment of nonformula-driven expenditures have meant that actual expenditures in Scotland appear to have differed, to Scotland's advantage, from the level implied by the strict application of the Barnett formula (Midwinter, 2002). However, the formula has been accepted as the basis for determining the assigned budget of the Scottish Parliament (and the budgets of other devolved territories), which together with the greater transparency produced by devolution, has led to a belief that the Barnett formula will play a more central role in the actual allocation in the future (Goudie, 2002).

\section{Barnett Equilibria}

In this paper we focus on the impact of the operation of the Barnett formula on a single devolved territory. We take the case of Scotland, but in principle the analysis can be replicated for any other region. Existing work on the Barnett formula attempts to reveal the evolution of Scottish per capita expenditure (covered by the assigned budget) under a strict Barnett regime and alternative scenarios concerning the exogenous growth in nominal comparable English expenditures and exogenous population changes. It is organised around the following relationship: 


$$
\frac{G_{S, t} / P_{S, t}}{G_{E, t} / P_{E, t}}=B\left(\bar{G}_{S, 0}, \bar{G}_{E, 0}, \ldots, \bar{G}_{E, t}, \bar{P}_{E, 0}, \ldots, \bar{P}_{E, t}, \bar{P}_{S, 0}, \ldots, \bar{P}_{S, t}\right)
$$

where $\mathrm{P}$ is population and the other terms are as defined above for equation 1.

This extant analysis has two main weaknesses. First, it is restrictive in that it simply charts the public finance implications of the operation of the Barnett allocation formula. We wish to focus on the impact of such changes on the real economy: that is, to identify the real, relative macroeconomic squeeze that matches the relative financial squeeze. Second, existing work is also conceptually flawed if the changes in devolved public expenditure have direct demographic implications. We would expect that adjustments in aggregate economic activity brought about by changes in government expenditure would influence migration flows, so that the spatial distribution of population becomes endogenous. We incorporate this endogeneity in our analysis.

In this paper we model the system-wide impacts on economic activity and population of the change in devolved government expenditure that would result if the Barnett formula were to be rigorously applied until relevant per capita expenditures in Scotland are equalized with those in England. We limit our investigation to the impact on a single region. Further, we adopt the smallregion assumption, so that changes in the region's activity, fiscal arrangements and population do not have impacts on the rest of the nation large enough for there to be perceptible feedback to the region itself.

We do not track the period by period changes in economic activity. Our main purpose is to explore the scale of the impacts on Scotland if per capita funding were to be equalized with England and to identify the factors magnifying/ reducing these effects. We therefore focus on the economic implications of achieving Barnett equilibria. We designate a Barnett equilibrium to be a spatial allocation of devolved expenditure (covered by the assigned budget) which, once reached, would be replicated by the subsequent operation of the Barnett formula. The impacts 
of reaching a Barnett equilibrium are identified under a range of assumptions concerning the nature of the regional economy and the detailed operation of the Barnett allocation mechanism. ${ }^{4}$

Where the Barnett population weights, taken at time period 0, are fixed, then the Barnett equilibrium is very straightforward to determine. In the two-region case, in time period the Barnett equilibrium ratio of relevant government expenditure in the two regions, $\mathrm{B}^{\mathrm{F}}$, where the $\mathrm{F}$ superscript stands for fixed population weights, is given as ${ }^{5}$ :

$$
B^{F}=\frac{G_{S, t}}{G_{E, t}}=\frac{\bar{P}_{S, 0}}{\bar{P}_{E, 0}}
$$

Our concern is to quantify the impact of the adjustment in government expenditure required to achieve the Barnett equilibrium on the level and composition of economic activity in Scotland. In order to isolate this impact, we keep all other exogenous Scottish and Rest of the UK (RUK) variables fixed. Essentially we impose the ceteris paribus assumption. As noted above, we are also operating with a stand-alone regional model that ignores inter-regional feedback effects. These combined exogeneity assumptions mean that the analysis simply concentrates on the impact of change in public expenditure in Scotland in a straightforward comparative static manner. In this case the Barnett equilibrium nominal government expenditure is given by:

\footnotetext{
${ }^{4}$ Barnett equilibria cannot be justified in terms of any public economic theory that we are aware of: there is no fundamental theoretical rationale for an equilibrium in which there is equality of per capita government expenditures across regions. However, this does not, of course, imply that the equilibria are uninteresting, since the stated basis of the funding of the devolved territories implies that the system moves towards such equilibria. It is of interest to explore what would happen if Barnett were strictly implemented.

${ }^{5}$ Further, this equilibrium is stable in the sense that in periods of increasing nominal government expenditure, the operation of the Barnett formula will drive the distribution towards the Barnett equilibrium, independently of the initial distribution. That is to say:

$\frac{G_{S, t}}{G_{E, t}} \rightarrow B^{F}$ as $G_{E, t} \rightarrow \infty$
} 


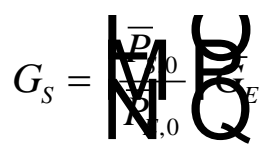

Whilst the exogeneity assumptions imposed in equation (4) appropriately focus the simulations, can they be justified? In particular, we know that nominal government expenditure in England (and also Scotland) must rise for a Barnett equilibrium to be reached with existing population weights. Will these increases not automatically violate the ceteris paribus assumptions that we have imposed?

The approach we adopt can be motivated in two ways. First, equation (4) could be thought of as resulting from purely nominal changes in the UK economy, with no changes in real exogenous variables aside from Scottish public expenditure. As long as the two economies are homogeneous of degree zero in prices, so that real variables are unaffected by equiproportionate changes in all prices, this interpretation is valid. A second justification for equation (4) is that it shows the proportionate deviations from the counterfactual that would occur in the Scottish economy if the Barnett equilibrium were imposed in a UK economy experiencing linear expansion. That is, an economy with all real exogenous variables (both Scottish and RUK) increasing at the same rate. In this case, provided that the economies are linear homogeneous in the real exogenous variables, so that changes in exogenous variables generate equiproportionate adjustments in real variables, this is a reasonable interpretation.

Up to now we have been considering the application of the Barnett formula with fixed population weights. However, as explained in the previous section, under the 1997 Darling amendment, the population weights used to calculate marginal nominal changes in assigned budgets are, if required, updated to reflect any changes in the population levels. Under this formulation a necessary condition for the economy to be in a Barnett equilibrium in time period $t$ would be that: 


$$
B^{V}=\frac{G_{S, t}}{G_{E, t}}=\frac{P_{S, t}}{P_{E, t}}
$$

where $\mathrm{B}^{\mathrm{V}}$ represents the Barnett equilibrium ratio with variable population weights (that is, with the full updating of those weights). Equation (5) indicates that in this case, Barnett equilibrium implies that covered nominal public expenditure per head will be equalised among devolved territories. ${ }^{6}$

In the single-region analysis, with again all exogenous variables - including English nominal government expenditure, prices and population - held constant, equation (5) implies:

$$
G_{S}=\beta P_{S}
$$

where $\beta=\frac{G_{E}}{P_{E}}$. Equation (6) captures the equilibrium operation of the Barnett mechanism in the allocation of expenditure. It is shown as the Barnett distribution line $\mathrm{B}^{\mathrm{V}}$ in Figure 1.

[Figure 1 near here]

But with population endogenous, there will be a second relationship between Scottish population and covered nominal expenditure that operates through the requirement for zero net migration in Barnett equilibrium. That is to say, for any given Scottish nominal expenditure, there will be a corresponding equilibrium population level consistent with the need to generate no desire for either net out- or in-migration. This can be expressed as:

$$
P_{S}=P_{S}\left(G_{S}\right)
$$

\footnotetext{
${ }^{6}$ In practice, population estimates are up-dated biennially, using the previous year's population estimate. This lagged response would, of course, matter for any period-by-period analysis of the formula, but in this paper we concentrate only on equilibria, which are unaffected by the presence of any lags in adjustment (given dynamic stability), including those relating to the up-dating of weights.
} 
with, again, all other exogenous variables held constant. Expression (7) identifies the equilibrium Scottish population level supported by a given level of nominal assigned budget with English activity, prices and population fixed and with other elements of Scottish final demand constant at their initial values. The specific character of the relationship expressed by equation (7) will depend upon the nature of the local economy and this is discussed in more detail in Sections 4

and 5. However, we expect $P_{S}(0), \frac{d P_{S}}{d G_{S}}>0$. Equation (7) is represented as the equilibrium population line, Z, in Figure 1. Simultaneously meeting the conditions represented by equations (6) and (7) generates the variable-weight Barnett equilibrium population and nominal Government expenditures. This is shown in Figure 1 as the intersection, E, between the lines $\mathrm{B}^{\mathrm{V}}$ and $\mathrm{Z}$.

In considering the stability of the variable-weight Barnett equilibrium, Figure 1 suggests that if there is one or more equilibria, then at least one will be stable in terms of the equilibrium relationships identified here. The Barnett distribution curve, $\mathrm{B}^{\mathrm{V}}$ must cut the equilibrium population curve $M$ from below. If the initial government allocation is above $\mathrm{G}_{\mathrm{s}}^{\mathrm{v}}{ }^{*}$, then the equilibrium population (read from line $\mathrm{Z}$ ) is below that required to justify that level of expenditure (as indicated by $\mathrm{B}^{\mathrm{V}}$ ). Expenditure falls, but then the subsequent population adjustment is insufficient to maintain that nominal government expenditure, until point $E$ is reached. Similarly, if the initial population is above $\mathrm{P}_{\mathrm{S}}{ }^{*}$, subsequent changes in the allocation of nominal expenditures are not large enough to maintain this population. The variable weight Barnett equilibrium is therefore stable, subject to exogenous shocks. Section 4 next outlines the economic features of the CGE model we employ, in Section 5, to simulate the impact of Barnett equilibria.

\section{The AMOS simulation model}


AMOS is a computable general equilibrium (CGE) modelling framework that is parameterised on data from a UK region, Scotland. ${ }^{7}$ A very brief description is presented in this section: more detail is available in the Appendix and a full listing of an earlier vintage of the AMOS model is provided in Harrigan et al (1991). The current version of AMOS has 3 transactor groups, namely households, corporations, and government; ${ }^{8} 25$ commodities and activities and two exogenous external transactor groups, the Rest of the UK and the Rest of the World (RUK and ROW). Throughout this paper commodity markets are taken to be competitive. We do not explicitly model financial flows, our assumption being that Scotland is a price-taker in competitive UK financial markets and, under the small open economy assumption, the interestrate-setting decisions of the Bank of England's Monetary Policy Committee are taken to be exogenous to Scotland.

Production is determined through cost minimisation with multi-level production functions. These are generally of a CES form but with Leontief and Cobb-Douglas available as special cases. For simplicity, in this paper all domestic intermediate transactions are Leontief. Otherwise we assume CES technology (notably for the production of value-added from capital and labour services) with "best guess" elasticities of substitution of 0.3 (Harris, 1989).

There are four major components of final demand: consumption, investment, exports and government expenditure. Of these, consumption varies proportionately with real disposable income. Exports (and imports) are generally determined via an Armington link (Armington, 1969) and are therefore relative-price sensitive with trade substitution elasticities of 2.0 (Gibson, 1990). Nominal government expenditure in Scotland is taken to be exogenous and the policy shocks involve changes to this variable. Of course when we have full updating of the Barnett formula there is a degree of endogeneity in that we link relevant government nominal expenditure

\footnotetext{
7 AMOS is an acronym for $A$ Macro-micro model $O$ f $S$ cotland. For a general review of CGE modelling see Greenaway et al, (1993) and for a apprais al of regional CGE models consult Partridge and Rickman (1998).

8 At present, AMOS treats Scotland as a self-governing economy, in the sense that there is only one consolidated government sector. Central government activity is partitioned to Scotland and combined with
} 
to the population level. Investment is initially set equal to depreciation although, as explained later in this section, in the short-run capital stock is endogenous.

In Section 5 we report the results of simulations under varying degrees of flexibility for the Scottish economy. The labour market is a potentially important source of inflexibility. In all the simulations reported in this paper we impose a unified local labour market characterised by perfect sectoral mobility. However, we simulate under two separate bargaining functions: regional bargaining and national bargaining. Under regional bargaining the regional real consumption wage is directly related to workers' bargaining power, and therefore inversely related to the regional unemployment rate (Minford et al, 1994). Even in a regional context, there is now widespread empirical support for this "wage curve" formulation (Blanchflower and Oswald, 1994). Here we take the parameters for the regional bargaining function from the econometric work reported by Layard et al. (1991):

$$
w_{s, t}=a-0.068 u_{s, t}+0.40 w_{s, t-1}
$$

where $\mathrm{w}_{\mathrm{s}}$ and $\mathrm{u}_{\mathrm{s}}$ are the natural logarithms of the Scottish real consumption wage and the unemployment rate respectively, $\mathrm{t}$ is the time subscript and a is a calibrated parameter. ${ }^{9}$

Under national wage bargaining, a small open region faces a nationally determined wage. Essentially this implies that the regional labour market is characterised by an exogenouslydetermined fixed nominal wage rate. This characterisation of the labour-market explicitly or implicitly characterises much UK theoretical and empirical regional analysis (Arup Economics and Planning, 2000; Harris, 1991; Holden and Swales, 1995; Roper and O'Shea, 1991).

local government activity. This is adequate for the present paper but a more sophisticated treatment of the public sector is part of the work plan under the ESRC Devolution project.

${ }^{9}$ The calibration is made so that the model, together with the set of exogenous variables, will recreate the base year data set. This calibrated parameter does not influence simulation outputs, but the assumption of initial equilibrium is, of course, important. 
A second key characteristic that determines the degrees of flexibility exhibited by the regional economy concerns population. Population is assumed to be either fixed or to be fully adjusted to the relevant changes in economic circumstances. Where population adjustment is allowed, it is driven by a relationship linking Scottish net migration positively (negatively) to the real wage (unemployment rate) differential with the rest of the UK. This variant of the Harris and Todaro (1970) approach is commonly employed in studies of US migration (e.g. Greenwood et al, 1991; Treyz et al, 1993). It is parameterised here from the econometrically estimated model reported in Layard et al. (1991):

$$
m=b-0.08\left(u_{s}-u_{r}\right)+0.06\left(w_{s}-w_{r}\right)
$$

where: $\mathrm{m}$ is the net in-migration rate (as a proportion of the indigenous population); $\mathrm{w}_{\mathrm{r}}$ and $\mathrm{u}_{\mathrm{r}}$ are the natural logarithms of the RUK real consumption wage and unemployment rates and $b$ is a calibrated parameter. ${ }^{10}$

The Scottish population is initially assumed to be in equilibrium. After an exogenous shock, full population adjustment implies a change in the population, with the attendant implications for the unemployment rate and the real wage rate, to the point where net migration falls to zero. Therefore setting $\mathrm{m}=0$ in equation (11) generates the following zero-net-migration relationship between the wage and unemployment rate:

$$
w_{s}=w_{r}+1.33\left(u_{s}-u_{r}\right)-\frac{b}{0.06}
$$

A third source of regional flexibility concerns adjustments to the capital stock. Again we assume that in the base period the capital stock is optimally adjusted. Under some simulations, the aggregate capital stock, and its sectoral composition, is held fixed at the base year values. In 
others, full capital adjustment is imposed, which implies that in each sector the actual and desired capital stock is re-equated, so that the capital rental rate equals the risk-adjusted user cost of capital.

If we simultaneously impose the regional bargaining option in the labour market and the migration function specified in equation (11), we have a CGE variant of the Layard, Nickell and Jackman regional model (Layard et al, 1991). This is our preferred model set up because there exists considerable supporting evidence for it. With the model parameterised in this way, equations (10) and (12) together determine the real wage and unemployment rate. This implies that, with unchanged values for the RUK real wage and unemployment rate, population equilibrium will reinstate the Scottish initial real wage and unemployment rate subsequent to any exogenous demand or ssupply shock apart from one to the bargaining or migration functions themselves (McGregor et al, 1995).

With both regional and national bargaining, imposing full capital and population adjustments in the face a demand disturbance produces no change in prices, the real wage or the unemployment rate. The economy acts as a population-endogenous input-output system (McGregor et al, 1996). Therefore the equilibrium population relationship - identified in the previous section and illustrated in Figure 1 - between nominal government expenditure and the population level is in this case linear.

\section{Simulating Barnett equilibria}

In the simulations reported in this paper, we are particularly interested in the neglected issues of population endogeneity, especially given the Darling amendment requiring the full updating of the population weights. To quantify these effects, we carry out alternative simulations with no population change and with full population change and with no and full updating of the

\footnotetext{
${ }^{10}$ Again, the calibrated parameter is to ensure population equilibrium (zero net migration) in the base year.
} 
population weights. However, we are also concerned with the quantitative impact of regional labour and capital market flexibility. We therefore undertake alternative simulations with regional and national wage bargaining and with no and full capital adjustment. This means that there are four economic and policy characteristics that vary between simulations. For each of these characteristics two options are allowed, so that we have a possible $16\left(2^{4}\right)$ sets of simulation results. $^{11}$

However, before reporting these results, Figure 2 extends the analysis used in Section 3 to illustrate the impact of population endogeneity in these simulations. Figure 2 is again drawn in nominal assigned-budget expenditure, $\mathrm{G}$, and population, $\mathrm{P}$, space. The initial equilibrium - that is, before the imposition of the Barnett equilibrium - is at $\mathrm{A}$, with population and expenditure $\mathrm{P}_{0}$, $\mathrm{G}_{0}$.

[Figure 2 near here]

There are three equilibrium population curves $-Z_{L}, Z^{R}{ }_{M}$ and $Z^{N}{ }_{M}$ - that pass through point $A$. These curves represent the long $\left(\mathrm{Z}_{\mathrm{L}}\right)$ and medium-run $\left(\mathrm{Z}^{\mathrm{R}}{ }_{\mathrm{M}}\right.$ and $\left.\mathrm{Z}^{\mathrm{N}}{ }_{\mathrm{M}}\right)$ relationships between population and nominal government expenditure imposed via the zero net migration condition. The long-run relationship is where the capital stock is allowed to optimally adjust. As noted in Section 4, for the AMOS model this relationship will be linear and is invariant to the nature of the bargaining function used. In the medium run, capital is held fixed and the equilibrium population relationship will depend on the wage setting function imposed in the recipient region. We therefore distinguish national and regional bargaining using the appropriate superscripts.

We expect the equilibrium population to be more sensitive to changes in government expenditure in the long run than in the medium run. The most straightforward way to think about this is to compare the situations under regional bargaining. In both the medium and long run, with

\footnotetext{
${ }^{11}$ In practice, a number of characteristic combinations produce the same outcome, so that only 10 sets of simulation results need to be reported.
} 
regional bargaining the real wage and unemployment rate take their base-period values. In both these time periods, the proportional population change will therefore equal the corresponding proportional employment change. However, in the medium run, the fixed real wage implies a reduction in the nominal wage with the cpi falling as a result of lower capital rental rates. On the other hand, in the long run the initial nominal wage is reinstated. The improved competitiveness of the medium-run Barnett equilibrium produces a lower proportionate reduction in employment - and therefore also population - in the medium run than in the long run.

It is difficult to rank, a priori, the sensitivity to government expenditure changes of the two medium-run equilibrium population curves. A relative fall in exogenous demand with fixed capital stock generates a fall in the cpi as capital rentals fall. Therefore with regional bargaining the nominal wage will fall, even though the real consumption wage is unchanged whilst with national bargaining the regional nominal wage is unchanged, so that the regional real wage will rise. This differential labour market response to the change in expenditure has implications for the slope of the corresponding equilibrium population curves. With regional bargaining, the imposition of the zero net migration condition reinstates the original unemployment rate and real wage (McGregor et al., 1995). But for national bargaining, population equilibrium will require the regional unemployment rate to rise, to offset the increased real consumption wage (equation 12). The increased unemployment rate will mean that for any given level of employment, population will be higher with national bargaining than with regional bargaining. However, the differential inflexibility in the regional labour market will imply that the medium-run employment effects of a reduction in relevant expenditure will be greater under national bargaining than regional bargaining. These two effects are operating in the opposite direction, as far as the impact on population is concerned. In the parameterisation adopted with the AMOS model, the differential competitiveness effect far outweighs the differential unemployment effect. This implies that equilibrium population is more sensitive to changes in government expenditure under national bargaining than regional bargaining. This is reflected in the way that the relevant curves have been drawn in Figure 2. 
Barnett equilibria with fixed population weights

Imposing the Barnett equilibrium for Scotland implies a reduction in relevant expenditure. Begin with the Barnett equilibrium with fixed weights. The new nominal DEL expenditure would be the initial Scottish population times the English per capita nominal DEL, $\beta$. With fixed population weights, this gives a new Scottish nominal expenditure that is independent of subsequent changes in population. It is represented in Figure 2 by the vertical line $\mathrm{B}^{\mathrm{F}}$. If population is fixed, the equilibrium is at $\mathrm{C}$. Population is at its original value $\mathrm{P}_{0}$ and the nominal expenditure falls to $\mathrm{G}^{\mathrm{F}}$. The value of other key economic variables will depend upon the degree of flexibility exhibited by other elements of the Scottish economy, for example the nature of the labour market and the degree of capital fixity.

If full population adjustment is allowed, Figure 2 shows three possibilities, indicated by points D, $\mathrm{E}$ and $\mathrm{F}$. The most straightforward case is where the capital stock is also allowed to fully adjust. The Barnett equilibrium is here at $\mathrm{F}$ and represents the input-output adjustment to the reduced government expenditure (McGregor et al, 1996). Output in all sectors will fall with a corresponding proportionate reduction in employment. Because the zero net migration condition implies no change in the unemployment rate, the proportionate fall in population will equal the proportionate fall in total employment. If the capital stocks are held fixed, the new equilibrium position depends on the imposed bargaining function. Where regional bargaining is adopted the equilibrium will be at point $\mathrm{D}$ in Figure 2: under national bargaining, the equilibrium is at $\mathrm{E}$. The population loss is greater for national bargaining, reflecting the more substantial fall in employment with national, as against regional, bargaining.

\section{Barnett equilibria with variable (up-dated) population weights}

In Figure 2, at point $\mathrm{C}$ the Scottish per capita expenditure equals the initial English figure. If there is to be constant updating of the Barnett weights, the equilibria must lie on the straight line 
from the origin through $\mathrm{C}$. This is simply a representation of equation (6) and the slope of the line is $\frac{1}{\beta}$.

If there is no population change, the issue of updating the weights in the Barnett formula simply does not arise. However, where the equilibrium population level does adjust to changes in nominal expenditure, unless the weights are amended, Barnett equilibrium expenditure per capita will continue to vary across the devolved regions. The interaction of endogenous population with the updating of the population weights in the Barnett formula leads to the appropriate equilibria shifting from $\mathrm{D}, \mathrm{E}$ and $\mathrm{F}$ to $\mathrm{G}, \mathrm{H}$ and $\mathrm{I}$. Points $\mathrm{D}, \mathrm{E}$ and $\mathrm{F}$ cannot be equilibria under variable population weights: indeed in every instance expenditure is higher than required for Barnett equilibrium. In each case, therefore, expenditure falls, inducing falls in population and further expenditure contraction as a result of the updating. From inspection of Figure 2, we expect that the population adjustment will be larger with full capital adjustment than where capital stock is fixed. Population is more responsive to changes in expenditure where capital stock adjusts, generating larger multiplier effects.

\section{Simulation results}

In order to attain greater precision for the population and government expenditure changes and to identify the impacts on other key economic variables, we perform an extensive set of simulations across different Barnett equilibria. The results for the change in real government expenditure, GDP and employment are given in Tables 1, 2 and 3. Each cell containing figures gives the result from a Barnett equilibrium simulation with a particular set of characteristics. The degree of capital fixity and the bargaining function used determine the row in which the result is reported. The population adjustment and the degree of updating of the Barnett population weights determine the column. Therefore, for example, the 10.72\% reduction in Scottish real government expenditure where: the capital stock is fixed and national bargaining is imposed, together with full population adjustment in the economy but no updating of the Barnett weights, 
is found in the $2^{\text {nd }}$ row and $2^{\text {nd }}$ column of Table 1 . In each cell in which results are reported, we have also shown - in the top right-hand corner - the point on Figure 2 to which the result corresponds.

Table 1 gives the proportionate change in real government expenditure in Scotland associated with the imposition of the various Barnett equilibria. An 11.26\% reduction in Scottish nominal expenditure is required to bring per capita 1999 nominal (assigned budget) expenditure in Scotland into line with the corresponding English figure for the same year. ${ }^{12}$ Therefore for simulations where the population is fixed or the population weights are not updated, this is the appropriate nominal change. This nominal adjustment therefore applies in the simulations reported in columns 1 and 2 in Table 1.

[Table 1 near here]

However, to identify changes in real government expenditure we need also to adjust for changes in the Scottish cpi. For the results where the imposition of a Barnett equilibrium generates no change in the Scottish cpi, the real and nominal government expenditure changes will be equal at $-11.26 \%$. For simulations with fixed population, this only applies where there is national bargaining and full capital adjustment. For simulations where population is fully adjusted but there is no change in the Barnett population weights, cpi is unchanged where capital fully adjusts, independent of the nature of the bargaining mechanism. In all the other cases reported in columns 1 and 2 in Table 1, the reduction in economic activity generates a fall in the cpi and this slightly mitigates the real impact of the nominal reduction in expenditure. In these cases the real government expenditure adjustment lies in the range $-10.82 \%$ and $-10.65 \%$.

Where there is full population adjustment and full updating of the Barnett population weights, the reduction in real government expenditure is markedly higher. These results are given in column 3

\footnotetext{
${ }^{12}$ This is expenditure as defined for the Government final demand column in the Scottish input-output tables.
} 
and range from $-12.43 \%$ to $-14.58 \%$. Comparing the figures in columns 2 and 3 of Table 1 reveals that the largest absolute and proportional additional fall in real government expenditure through the imposition of the Darling amendment to the Barnett formula occurs where there is also full capital adjustment. This is the shift represented by the movement from $\mathrm{F}$ to I in Figure 2.

In analysing the economic effects of these reductions in real government expenditure, we begin with the results from the fixed population simulations. These simulations reflect the belief that population would be unaffected by the government demand changes; a view that existing studies of Barnett formula impacts usually adopt. In this case there are no population adjustments and no requirement for the updating of the population weights in the Barnett formula.

The GDP and employment changes are given in the first column of Tables 2 and 3. (These are read in an exactly analogous manner to Table 1, with the degree of capital fixity and wage bargaining governing the row and population adjustment and the degree of weight up-dating deciding the column.) For both the fixed capital and full capital adjustment cases, the reduction in activity is greater with national bargaining than regional bargaining. The reason is quite straightforward. With regional bargaining, the nominal wage will fall with the reduction in exogenous demand as unemployment rises and the cpi falls. This improves competitiveness reduces the negative impact on the Scottish economy. With national bargaining there is no downward pressure on wages and the negative effects of the government expenditure changes are therefore much greater.

[Table 2 near here]

With a constant population, the impact on activity of allowing full capital adjustment differs between the two bargaining models. With national bargaining, a fixed capital stock goes someway to cushioning the impact of the reduced government expenditure. Although nominal wages are unchanged, capital rentals fall, so that competitiveness improves. Therefore some 
increase in regional exports partially offsets the fall in real government expenditure. However, full capital adjustment leads to capital rentals returning to their base-period levels as disinvestment occurs. This produces a model that corresponds to an extended input-output with investment and social security payments endogenous (Batey, 1985). The reduction in both employment and GDP in this case is large, at 3.30\% and 3.61\% respectively.

The fixed-population, regional bargaining simulations are very different. In this case, with capital fixed, the fall in the nominal wage associated with the Barnett equilibrium underpins an increase in output and employment in many trade-orientated sectors, as their price competitiveness improves. For these sectors, the capital rental rate actually rises together with the fall in the capital rental rates in those sectors dominated by government demand. The impact of allowing full adjustment of the capital stock is to stimulate activity in the trade-orientated sectors by more than the reduction in activity in the government-dominated sectors. The additional net effect of allowing full capital adjustment here is therefore positive on both GDP and employment, which now fall by slightly less. With population fixed and regional bargaining, the impact on Scottish GDP is in the range -1.22 to -1.27 and employment -1.40 and -1.46 .

[Table 3 near here]

Incorporating the full population adjustment, but no updating of the population weights in the Barnett formula, gives the results reported in column 2 of Tables 2 and 3. The range of GDP reductions under these circumstances is $-1.75 \%$ to $-3.56 \%$, with the employment reduction range being $-2.27 \%$ to $-3.88 \%$. The main impact of imposing the population adjustment is on the real wage in the simulations adopting regional bargaining. Under regional bargaining, allowing full population adjustment increases the real wage to its original level, and this means reinstating the original nominal wage where full capital adjustment is also imposed. These wage adjustments for the regional bargaining and full capital adjustment simulation increase the absolute size of the GDP reduction from $1.22 \%$ to $3.56 \%$. Where there is national bargaining, allowing population adjustment has no impact on the nominal wage and the additional effects come primarily through 
changes in consumption demand, stemming from lower social security payments. It is useful to note that where population is endogenous and fully adjusted, for all the regional bargaining and all the full capital adjustment simulations, the percentage change in population equals the percentage change in employment. For the simulation with capital fixed and national bargaining, the population loss $(2.64 \%)$ is a little less than the reduction in employment $(2.70 \%)$.

Finally, the results that include the updating of the Barnett formula weights are given in the third column of Tables 2 and 3. Comparing these results with the corresponding figures in column 2 gives the effect that the full updating of the population weights has on the level of Scottish activity in Barnett equilibrium. This impact is always to magnify the absolute size of the fall in activity. It is relatively small where the capital stock is fixed: the absolute size of the reduction in activity is increased by less than $20 \%$. However, where there is full capital stock adjustment the simultaneous full updating of the population weights increases the negative impact on employment and GDP by almost 30\%. Again, for these simulations, the $\%$ change in population is the same as the \% change in employment except where there is national bargaining with a fixed capital stock. In that case, population falls by $3.16 \%$ as against the employment reduction of $3.23 \%$.

\section{Sectoral disaggregation}

Figures 3 and 4 present sectorally disaggregated Barnett equilibrium results for the model with regional bargaining and, where appropriate, with full updating of the Barnett formula population weights. This is our favoured treatment of the labour market because it is based on an econometrically estimated wage curve. Results are given for time intervals delineated by the degree of capital and population fixity. These are the short, medium and long runs. The short run has both population and capital stocks fixed. The medium run has population fully adjusted but capital stocks fixed. The long run has full adjustment for both population and capital stocks. These simulations therefore correspond to points $\mathrm{C}, \mathrm{G}$ and $\mathrm{I}$ in Figure 2. Figure 3 gives the 
percentage sectoral GDP (value added) changes and Figure 4 the corresponding employment changes

[Figures 3 and 4 near here]

It is clear that the reduction in activity is focused on the two sectors "Public Administration and Defence" and "Education, Health and Social Work". This concentration of effects is not surprising since these sectors bear the brunt of the direct reduction in expenditure. However, in

the short run the majority of the other sectors experience an increase in activity, as falling nominal wages and intermediate prices increase competitiveness and generate labour market "crowding in". In the medium run, the full population adjustment, and further fall in government expenditure, reduces any initial employment gains, and ten out of the twenty five sectors now show employment losses. Once the full capital stock adjustment is also incorporated, activity falls in all sectors as the simulations replicate an extended input-output system.

Overall, the results emphasise the critical importance of population adjustment in determining the scale of Barnett-induced relative contractions in activity, and the significance of moving to a system of variable population proportions. In effect, the Darling amendment to the Barnett formula eliminates a significant element of automatic stabilisation from the regional system of the UK.

\section{Conclusions}

The simulation results point to a potentially sizeable contractionary impact of Barnett equilibria in Scotland and the importance of the wage-bargaining, migration and capital adjustment processes in governing the likely scale of these effects. Under regional bargaining, if population is fixed, the size of the reduction in regional activity in Barnett equilibrium is relatively small. The reduction in GDP and employment is less than $1.3 \%$ and $1.5 \%$ respectively. Moreover, as the capital stock adjusts this makes little difference to the change in aggregate activity. However, 
with endogenous population, even with no updating of the Barnett weights, the negative impact on Scottish economic activity is considerably increased. This is particularly true where capital adjustment occurs. Finally, if the population weights in the Barnett formula are constantly updated, the real reduction in government expenditure, and the corresponding reduction in activity, is further intensified. With full capital and population adjustment, the Darling-amended Barnett equilibrium implies a $4.61 \%$ reduction in Scottish GDP and a 5.03\% reduction in Scottish employment and population. While certainly substantial, these results may not be large relative to other possible disturbances to the Scottish economy, such as the projected decline in Scotland's population of working age, although variable population proportions in the Barnett formula will operate to reinforce such disturbances (Lisenkova et al, 2006).

While our analysis represents a significant generalisation of past work, there remain four important areas for further research. First, while we concentrate here on the implications of Barnett equilibria, we know that these are only attained after a substantial lag, reflecting delays in up-dating population weights, the incremental nature of the formula and the typically extended nature of migration and capital stock adjustment processes. The adjustment process clearly merits further investigation.

Second, our assumption that the expenditure changes analysed here constitute a pure demand disturbance considerably simplifies our analysis. It allows us to focus on this critical but previously neglected aspect of the formula. However, adverse supply-side impacts may well accompany the relative expenditure contractions, so that the estimates we present cannot be regarded as providing a "worst case" scenario. There are at least two relevant aspects to this. First, the reduction in real government expenditure might directly reduce productive efficiency by limiting policies aimed at improving local development and skills. Second, if the reduction in real per capita government expenditure lowers the amenity value associated with living in Scotland, this will further encourage out-migration and generate an increase in the real wage so as to satisfy the zero net migration requirement. These supply impacts merit further investigation. 
Third, our analysis explores the impact of Barnett on economic activity in Scotland alone. The extensive use of the small-region assumption means that inter-regional spillovers and national macro-economic constraints are ignored. We know from the existing distribution of per capita government expenditures that adherence to Barnett implies that Wales will be subject to smaller, and Northern Ireland greater, contractions in demand than Scotland. The economy of England will, however, benefit, but identification of the scale of the impacts necessitates the use of an explicitly interregional modelling framework.

A fourth area is the investigation of a wider range of alternative schemes for distributing public expenditures among the regions of the UK. A number of authors have argued that the strict imposition of the Barnett formula is unsustainable (Christie, 2002; McLean and McMillan, 2003). At the simplest level, should up-dated "needs assessments" become available, it would, of course, be instructive to compare the implied needs equilibria with the corresponding Barnett equilibria, but the last publicly available needs assessment relates to 1976-77 (reported in HM Treasury, 1979). However, a number of variants of greater fiscal autonomy have been proposed and future research should explore the possible impact of alternative fiscal systems in a UK context in future research. (See, for example, McGregor and Swales (2005) and McGregor, Swales and Yin (2003).)

The neglected system-wide effects of the Barnett formula are important in practice. Yet alternatives to Barnett are often framed essentially in terms of microeconomic "needs". If the macroeconomic consequences of Barnett really matter, as our analysis suggests, they should feature more heavily in decisions concerning the regional distribution of government expenditures. 


\section{ACKNOWLEDGMENTS}

The authors acknowledge the support of the ESRC (grant L219252102) under the Devolution and Constitutional Change Research Programme and, latterly, under the joint ESRC/ Scottish Executive's Scottish Demography Initiative. The Centre for Public Policy for Regions (CPPR) is a SHEFC-funded joint research institute of the Universities of Glasgow and Strathclyde. We are very grateful to two anonymous referees for constructive criticism that significantly improved the paper and to Alex Christie, Scottish Economic Policy Network and CPPR, for discussions on a number of aspects of the Barnett formula. We are also indebted to participants in seminars on related material at Aberdeen, Dundee and St. Andrews Universities; the International Regional Science Association Annual Conference, British and Irish Section, Brighton, August 2002; David Hume Institute, December, 2002; Southern Regional Science Association, Louisville, Kentucky, April, 2003; Fourth Israeli/British and Irish Regional Science Workshop, Edinburgh, May, 2003, the Royal Economic Society Conference, Nottingham, April, 2005 and the North American Regional Science Conference, Las Vegas, November, 2005. Linda Ferguson is now with the Research Department of Glasgow City Council and David Learmonth is currently employed by the Bank of England. The research reported in this paper was conducted while both were Research Assistants at the Fraser of Allander Institute. 


\section{REFERENCES}

Armington, P. (1969), "A Theory of Demand for Products Distinguished by Place of Production", IMF Staff Papers, vol.16, pp. 157-178.

Arup Economics and Planning (2000), "Evaluation of Regional Selective Assistance: Report for

DTI, National Assembly for Wales and Scottish Executive", Arup Economics and Planning, London.

Batey, P.W.J. (1985), "Input-Output Models for Regional Demographic-Economic Analysis: Some Structural Comparisons", Environment and Planning A, vol. 17, pp. 73-99.

Bell, D., Dow, S., King, D. and Massie. N. (1996), "Financing Devolution", Hume Papers on Public Policy, Edinburgh University Press, vol. 4, No.2.

Blanchflower, D. and Oswald, A. (1994), The Wage Curve, MIT Press, Cambridge, MA.

Christie, A. (2002), "The 1979 Needs Assessment: Lessons from Australia and Canada", Fraser of Allander Quarterly Economic Commentary, July 2002, pp. 30-35.

Cuthbert, J. (2001), "The Effect of Relative Population Growth on the Barnett Squeeze", Fraser of Allander Quarterly Economic Commentary, May 2001, pp. 34-37.

Edmonds, T., (2001) “The Barnett Formula”, House of Commons Research Paper, 01/108.

Ferguson, L., Learmonth, D., McGregor, P.G., Swales, J.K. and Turner, K. (2003), "The Impact of the Barnett Formula on the Scottish Economy: A General Equilibrium Analysis", Strathclyde Discussion Papers in Economics, No. 03-04. 
Gibson, H. (1990), "Export Competitiveness and UK Sales of Scottish Manufacturers", Working Paper, Scottish Enterprise, Glasgow.

Goudie, A. (2002), "GERS and Fiscal Autonomy", Scottish Affairs, No. 41, pp. 56-85.

Greenaway, D., Leyborne, S.J., Reed G.V. and Whalley J. (1993), Applied General Equilibrium Modelling: Applications, Limitations and Future Developments, HMSO, London.

Greenwood, M.J., Hunt, G., Richman, D. and Treyz, G. (1991), "Migration, Regional Equilibrium, and the Estimation of Compensating Differentials", American Economic Review, vol. 81, pp. 1382-90.

Harrigan, F., McGregor, P., Perman, R., Swales, K. and Yin, Y.P. (1991), “AMOS: A Macro-Micro Model of Scotland", Economic Modelling, vol. 8, pp. 424-479.

Harris, J. R. and Todaro, M. P. (1970), "Migration, Unemployment, and Development: A Two-Sector Analysis", American Economic Review, vol. 60, pp. 126-142.

Harris, R.I.D. (1989) The Growth and Structure of the UK Regional Economy, 1963-1985, Avesbury, Aldershot.

Harris, R.I.D. (1991), "The Employment Creation Effects of Factor Subsidies for Northern Ireland Manufacturing Industry, 1955-1983”, Journal of Regional Science, vol. 31, pp. 4964. 
Heald, D. A. (1996), "Formula-Controlled Territorial Public Expenditure in the United Kingdom", Public Finances/Finances Publiques, vol. 8, pp. 23-52.

Heald, D.A. and McLeod, A. (2002a), "Beyond Barnett: Financing Devolution", in J. Adams and P. Robinson (eds.) Devolution in Practice: Public Policy Differences within the UK, IPPR, London

Heald, D. A. and McLeod, A. (2002b) "Public Expenditure" in Constitutional Law, The Laws of Scotland: Stair Memorial Encyclopaedia, especially paragraph 535. (Edinburgh: Buttersworth)

HM Treasury (1979), Needs Assessment Study - Report, HM Treasury, London.

HM Treasury (1997), Principles to Govern Determination of the Block Budgets for the Scottish Parliament and National Assembly for Wales, December 1997.

HM Treasury (2004), Funding the Scottish Parliament, National Assembly for Wales and Northern Ireland Assembly, Fourth Edition, Stationary Office, London.

Holden, D.R. and Swales, J.K. (1995), "The Additionality, Displacement and Substitution Effects of a Factor Subsidy", Scottish Journal of Political Economy, vol. 42, pp. 113-126.

Kay, N. (1998), "The Scottish Parliament and the Barnett Formula." Fraser of Allander Quarterly Economic Commentary, Vol. 24, No 1, pp. 32-48.

Layard, R., Nickell, S. and Jackman, R. (1991), Unemployment: Macroeconomic Performance and the Labour Market, Oxford University Press, Oxford. 
Lisenkova, K, McGregor, P G, Pappas, N, Swales, K, Turner, K, and R Wright. (2006), "The macroeconomic impact of projected population decline in Scotland: a computable general equilibrium analysis", University of Strathclyde, Department of Economics mimeo.

McCrone, G. (1999), "Scotland's Public Finances from Goshen to Barnett", Fraser of Allander Institute Quarterly Economic Commentary, Vol. 24, No. 2, pp. 30-46.

McGregor, P. G. and Swales, J. K. (2005) "Economics of Devolution/ Decentralization in the UK: Some Questions and Answers”, Regional Studies, vol. 39.4, pp477-494.

McGregor, P.G., Swales, J.K. and Yin, Y.P. (1995), 'Migration Equilibria /Disequilibria and the Natural Rate of Unemployment in a Regional Context", International Journal of Manpower, vol. 16, pp. 66-72.

McGregor, P.G., Swales, J.K. and Yin, Y.P. (1996), "A Long-run Interpretation of Regional Input-Output Analysis", Journal of Regional Science, vol. 36, pp. 479-501.

McGregor, P.G., Swales, J.K. and Yin, Y.P. (2003), "The Macroeconomics of Scottish Fiscal Autonomy: Inverted Haavelemo Effects in a General Equilibrium Analysis of the "Tartan Tax'", paper presented to the British and Irish Regional Science Association Conference, St Andrews.

McLean, I. and McMillan, A. (2003), "The Distribution of Public Expenditure across the UK Regions", Fiscal Studies, vol. 24, pp. 45-71.

Midwinter, A. (2000), "Devolution and Public Spending: Arguments and Evidence", Fraser of Allander Quarterly Economic Commentary, Vol. 25, No. 4, pp. 38-48. 
Midwinter, A. (2002), "The Limits to Full Fiscal Autonomy: A Critique of the Scottish National Party's Agenda for Devolution Finance", Scottish Affairs, No. 41, pp. 121.

Minford, P., Stoney, P., Riley, J. and Webb, B. (1994), "An Econometric Model of Merseyside: Validation and Policy Simulations", Regional Studies, vol. 28, pp. 563-575.

Partridge, M.D. and Rickman, D.S. (1998), 'Regional Computable General Equilibrium Modelling: A Survey and Critical Appraisal', International Regional Science Review, vol. 21, pp. 205-248.

Roper, S. and O'Shea, G. (1991), “The Effects of Labour Subsidies in Northern Ireland 196779: A Simulation Exercise", Scottish Journal of Political Economy, vol. 38, pp. 273-292.

Treyz, G.I., Rickman, D.S., Hunt G.L. and Greenwood, M.J. (1993), "The Dynamics of Internal Migration in the U.S.", Review of Economics and Statistics, vol. 75, pp. 209-214.

Twigger, R. (1998), "The Barnett Formula." House of Commons Library: Economic Policy and Statistics Section, Research Paper, No. 98/8. 


\section{Appendix}

\section{A Condensed Version of the AMOS CGE Model}

\begin{tabular}{|c|c|}
\hline (1) Commodity Price & $p_{i}=p_{i}\left(w_{n}, w_{k i}\right)$ \\
\hline (2) Consumer Price Index & $c p i=\sum_{i} \theta_{i} p_{i}+\sum_{i} \theta_{i}^{U K} \bar{p}_{i}^{U K}+\sum_{i} \theta_{i}^{R O W} \bar{p}_{i}^{R O W}$ \\
\hline (3) Capital Price Index & $k p i=\sum_{i} \gamma_{i} p_{i}+\sum_{i} \gamma_{i}^{U K} \bar{p}_{i}^{U K}+\sum_{i} \gamma_{i}^{R O W} \bar{p}_{i}^{R O W}$ \\
\hline (4) User Cost of Capital & $u c k=u c k(k p i)$ \\
\hline $\begin{array}{c}\text { (5) Nominal Wage Setting } \\
\text { Regional Bargaining }\end{array}$ & $w_{n}=w_{n}$ \\
\hline National Bargaining & $w_{n}=\bar{w}_{n}$ \\
\hline (6) Labour Force: & \\
\hline $\begin{array}{l}\text { Short-Run } \\
\text { Full Adjustment }\end{array}$ & $\begin{array}{l}L=\bar{L} \\
L=L \overline{\bar{c}}_{\bar{c} \boldsymbol{i} i}, N\end{array}$ \\
\hline (7) Labour Demand & $N_{i}^{D}=N_{i}^{D}\left(Q_{i}, w_{n}, w_{k, i}\right)$ \\
\hline (8) Labour Market Clearing & $\sum_{i} N_{i}^{D}=N$ \\
\hline (9) Capital Demand & $K_{i}=K_{i}^{D}=K_{i}^{D}\left(Q_{i}, w_{n}, w_{k, i}\right)$ \\
\hline (10) Capital Rental Rate & \\
\hline $\begin{array}{l}\text { Short-Run } \\
\text { Full Adjustment }\end{array}$ & $\begin{array}{l}w_{k, i}=w_{k, i}^{s} \boldsymbol{G}_{i}^{d}, \bar{K}_{i}^{s} \mathbf{Y} \\
w_{k, i}=w_{k, i}^{l} \boldsymbol{D e t}_{k} \mathbf{(}\end{array}$ \\
\hline (11) Nominal Household Income & $Y=\Psi_{n} N w_{n}+\Psi_{k} \sum_{i} K_{i} w_{k, i}$ \\
\hline (12) Commodity Demand & $Q_{i}=C_{i}+I_{i}+G_{i}+X_{i}$ \\
\hline
\end{tabular}




\begin{tabular}{|l|l|}
\hline (13) Consumption Demand & $C_{i}=C_{i}\left(p_{i}, \bar{p}_{i}^{U K}, \bar{p}_{i}^{\text {ROW }}, Y, c p i\right)$ \\
\hline (14) Capital Stock Adjustment & $\Delta K_{i}=d_{i} K_{i}$ \\
\hline (15) Investment Demand & $I_{i}=I_{i}\left(p_{i}, \bar{p}_{i}^{U K}, \bar{p}_{i}^{R O W}, \sum_{i} b_{i, j} \Delta K_{j}\right)$ \\
\hline $\begin{array}{l}\text { (16) Government Demand } \\
\text { No Population Updating } \\
\text { Full Population Updating }\end{array}$ & $G_{i}=G_{i}^{s}\left(\bar{G}^{n}, c p i\right)$ \\
& $G_{i}=G_{i}^{l}(L, c p i)$ \\
\hline (17) Export Demand & $X_{i}=X_{i}\left(p_{i}, \bar{p}_{i}^{U K}, \bar{p}_{i}^{\text {ROW }}, \bar{D}^{U K}, \bar{D}^{\text {ROW }}\right)$ \\
\hline
\end{tabular}

\section{NOTATION}

\section{Activity-Commodities}

$\mathrm{i}, \mathrm{j}$ are activity/commodity subscripts.

\section{Transactors}

UK = United Kingdom, ROW = Rest of World

Time Periods

$\mathrm{s}=$ short run, $1=$ full adjustment

Nominal/Real

Variables are generally expressed in real terms apart from where the superscript $\mathrm{n}$ is used.

\section{Functions}

$\mathrm{p}($.$) \quad cost function$

uck(.) user cost of capital formulation

$\mathrm{w}_{\mathrm{n}}(),. \mathrm{w}_{\mathrm{k}}($.$) \quad factor price setting functions$

$\mathrm{C}(),. \mathrm{I}(),. \mathrm{X}($.) Armington consumption, investment and export demand functions, Homogenous of degree zero in prices and one in quantities

$\mathrm{K}^{\mathrm{D}}(),. \mathrm{N}^{\mathrm{D}}($.$) \quad factor demand functions$

L zero net migration condition

G Barnett pulic sector expenditure formula 


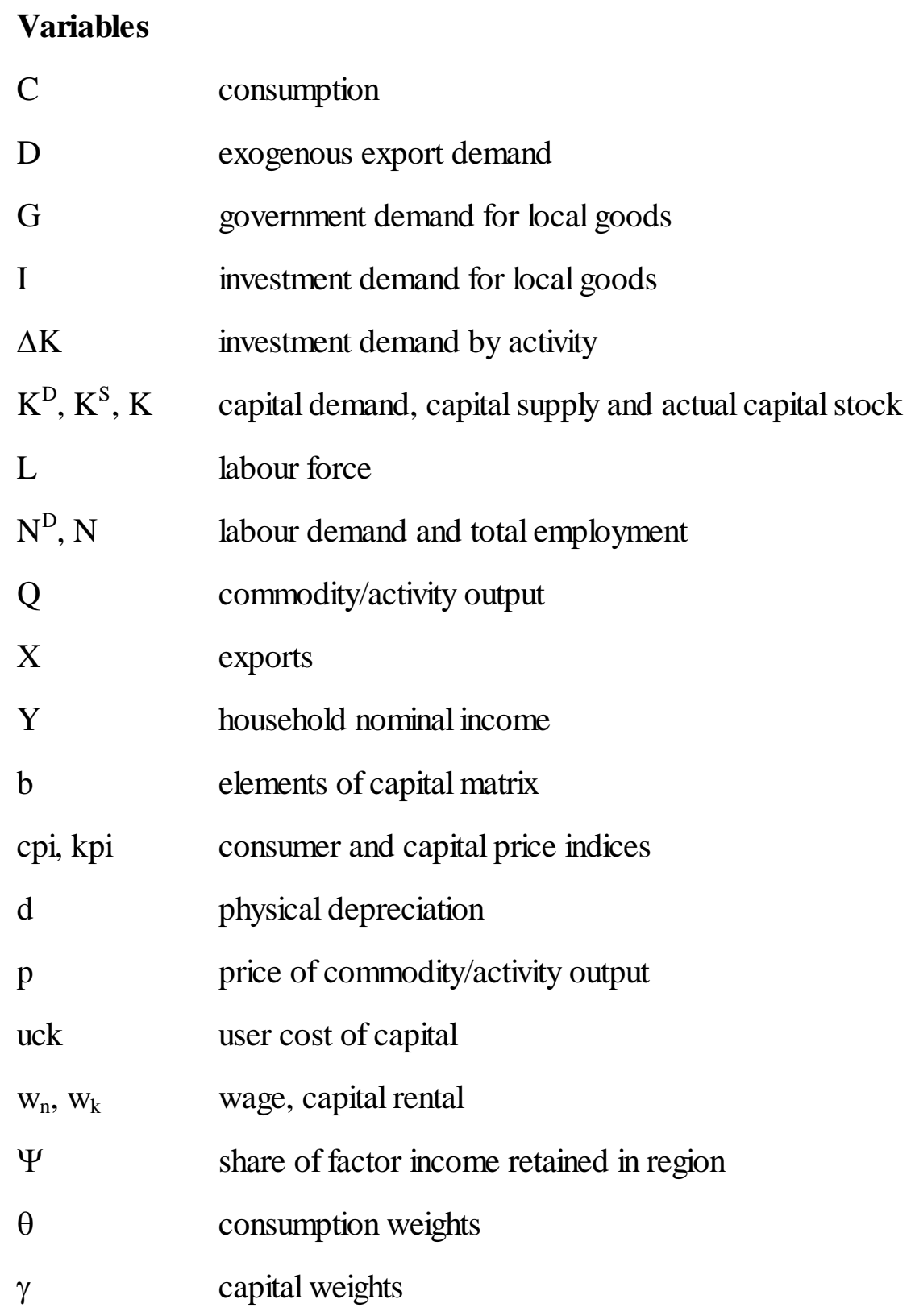

Notes : A number of simplifications are made in this condensed version of AMOS

1. Intermediate demand is suppressed throughout (e.g. only primary factor demands are noted in price determination in equation (1) and final demands in the determination of commodity demand in equation (12).

2. Income transfers are generally suppressed.

3. Taxes are ignored. 
4. The participation rate is ignored. 
Table 1: The percentage change in Scottish real government expenditure across different Barnett equilibria.

\begin{tabular}{|c|c|c|c|c|}
\hline \multirow{3}{*}{$\begin{array}{l}\text { Capital } \\
\text { Adjustment }\end{array}$} & \multirow[t]{3}{*}{ Wage Bargaining } & \multicolumn{3}{|c|}{ Population Adjustment } \\
\hline & & \multirow[t]{2}{*}{ Fixed } & \multicolumn{2}{|c|}{ Full } \\
\hline & & & $\begin{array}{c}\text { No updating } \\
\text { Barnett weights }\end{array}$ & $\begin{array}{c}\text { Full updating } \\
\text { Barnett weights }\end{array}$ \\
\hline \multirow[t]{3}{*}{ Fixed } & Regional & $\mathrm{C}$ & $\mathrm{D}$ & $\bar{G}$ \\
\hline & & -10.65 & -10.69 & -12.43 \\
\hline & National & -10.78 & -10.72 & -12.81 \\
\hline \multirow[t]{4}{*}{ Full } & Regional & $\mathrm{C}$ & \multirow{4}{*}{-11.26} & \multirow{4}{*}{-14.58} \\
\hline & & -10.82 & & \\
\hline & National & $\mathrm{C}$ & & \\
\hline & & -11.26 & & \\
\hline
\end{tabular}

Notes: The letter in the top right-hand corner of individual cells indicates the corresponding point on Figure 2.

Table 2: The percentage change in Scottish GDP across different Barnett equilibria.

\begin{tabular}{|c|c|c|c|c|}
\hline \multirow{3}{*}{$\begin{array}{l}\text { Capital } \\
\text { Adjustment }\end{array}$} & \multirow[t]{3}{*}{ Wage Bargaining } & \multicolumn{3}{|c|}{ Population Adjustment } \\
\hline & & \multirow[t]{2}{*}{ Fixed } & \multicolumn{2}{|c|}{ Full } \\
\hline & & & $\begin{array}{c}\text { No updating } \\
\text { Barnett weights }\end{array}$ & $\begin{array}{c}\text { Full updating } \\
\text { Barnett weights }\end{array}$ \\
\hline \multirow[t]{3}{*}{ Fixed } & Regional & $\mathrm{C}$ & $\mathrm{D}$ & $\mathrm{G}$ \\
\hline & & -1.27 & -1.75 & -2.04 \\
\hline & National & $\begin{array}{ll} & C \\
-1.99 & \\
\end{array}$ & -2.02 & $\begin{array}{rr} & \mathrm{H} \\
-2.41 & \\
\end{array}$ \\
\hline \multirow[t]{3}{*}{ Full } & Regional & $\mathrm{C}$ & \multirow{3}{*}{-3.56} & \multirow{3}{*}{-4.61} \\
\hline & & -1.33 & & \\
\hline & National & $\begin{array}{ll} & C \\
-3.30 & \\
\end{array}$ & & \\
\hline
\end{tabular}

Notes: The letter in the top right-hand corner of individual cells indicates the corresponding point on Figure 2. 
Table 3: The percentage change in Scottish employment across different Barnett equilibria.

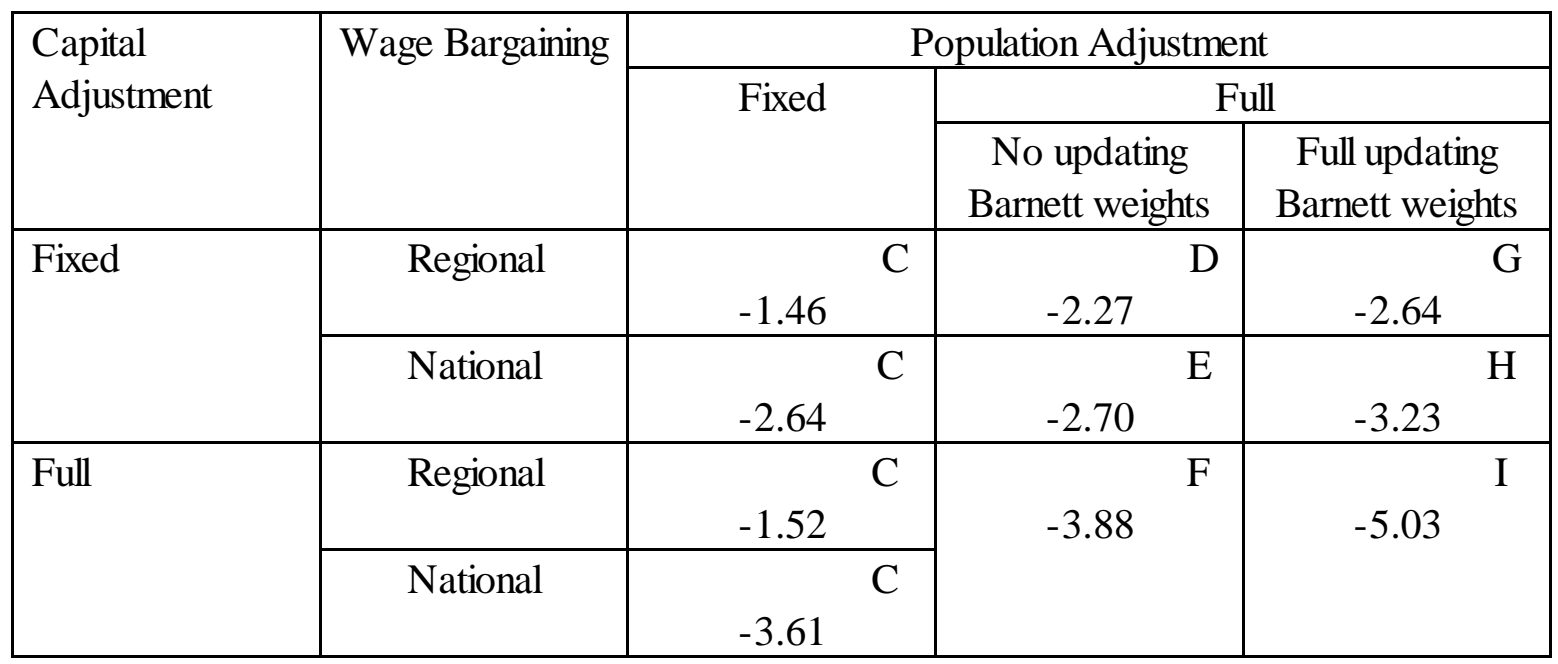

Notes: The letter in the top right-hand corner of individual cells indicates the corresponding point on Figure 2. 
Figure 1: The equilibrium population and government expenditure with Barnett equilibrium (variable weights)

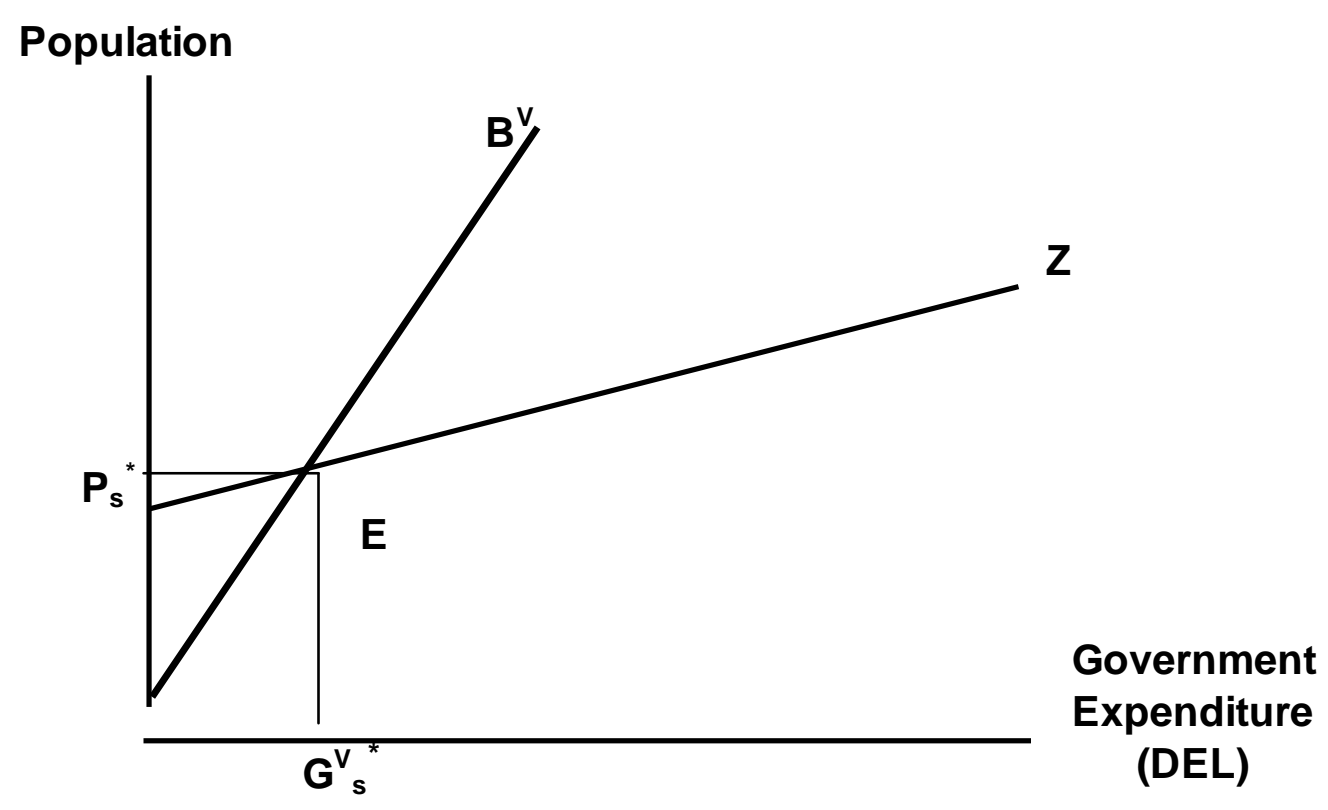

Figure 2: Barnett equilibria DEL and population levels under various assumptions concerning labour and capital market flexibility

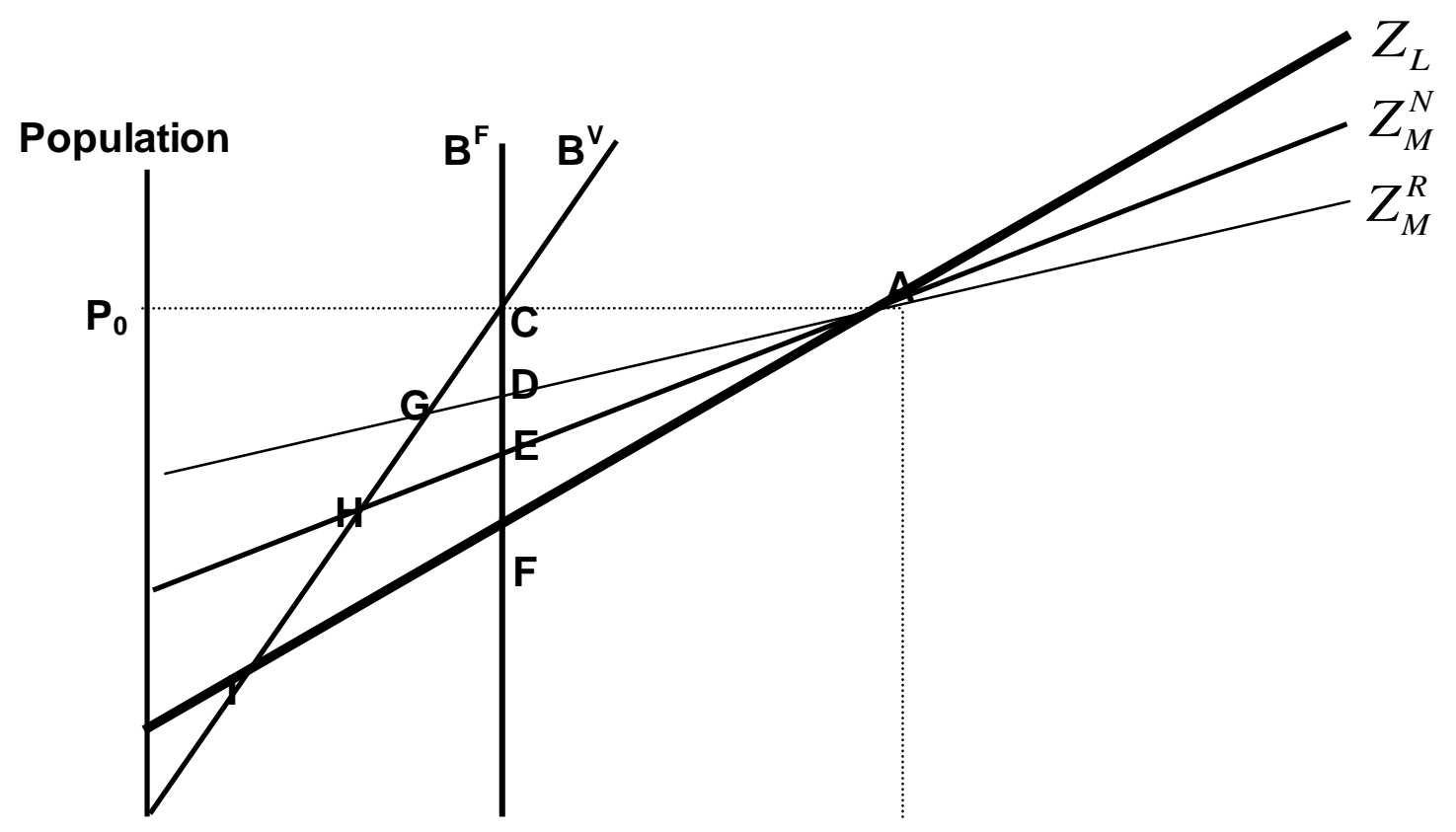




\section{$G^{F} \quad G_{0} \quad$ Government \\ Expenditure \\ (DEL)}

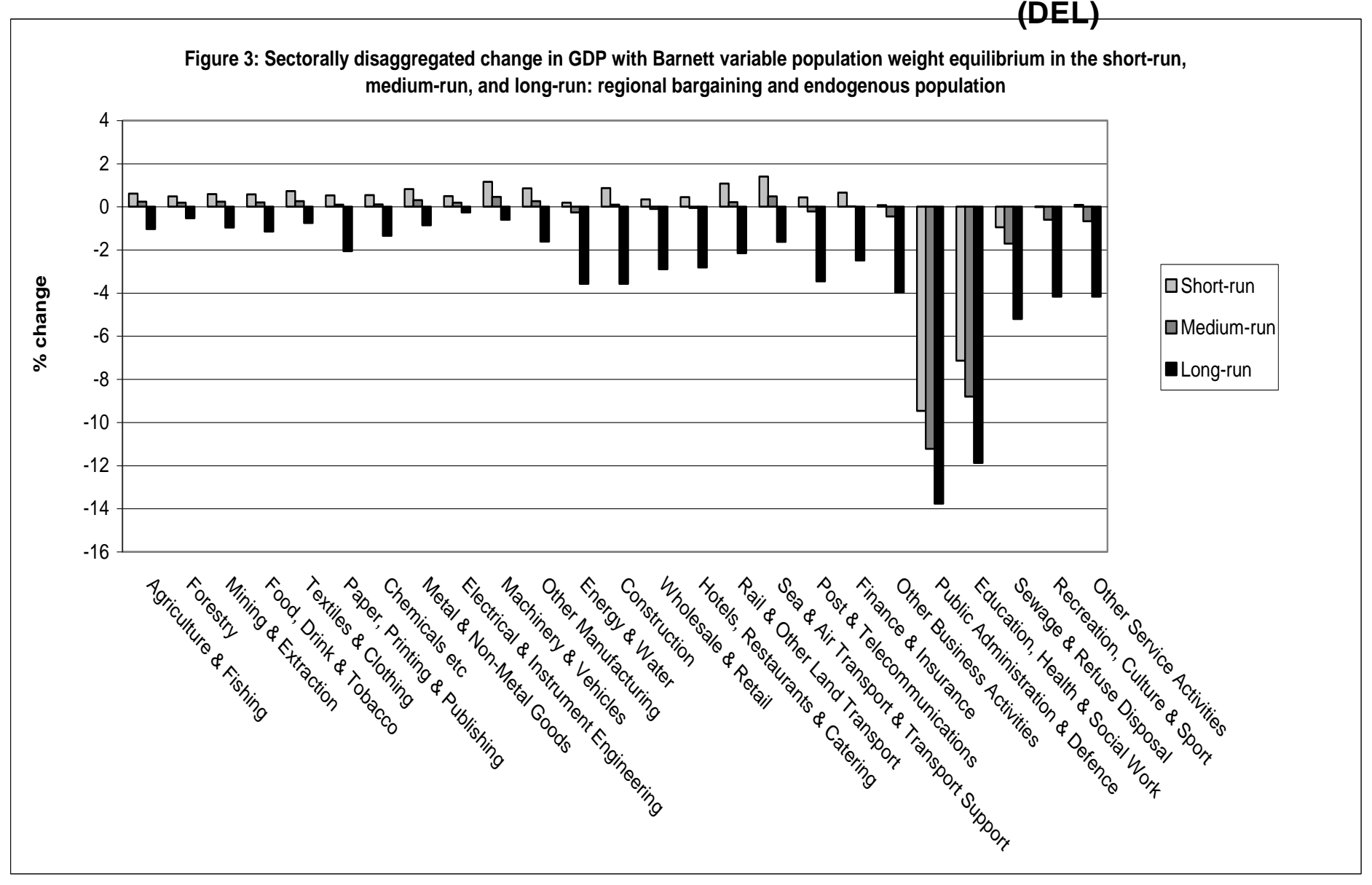

Figure 4: Sectorally disaggregated change in employment with Barnett variable population weight equilibrium in the short-run, medium-run, and long-run: regional bargaining and endogenous population

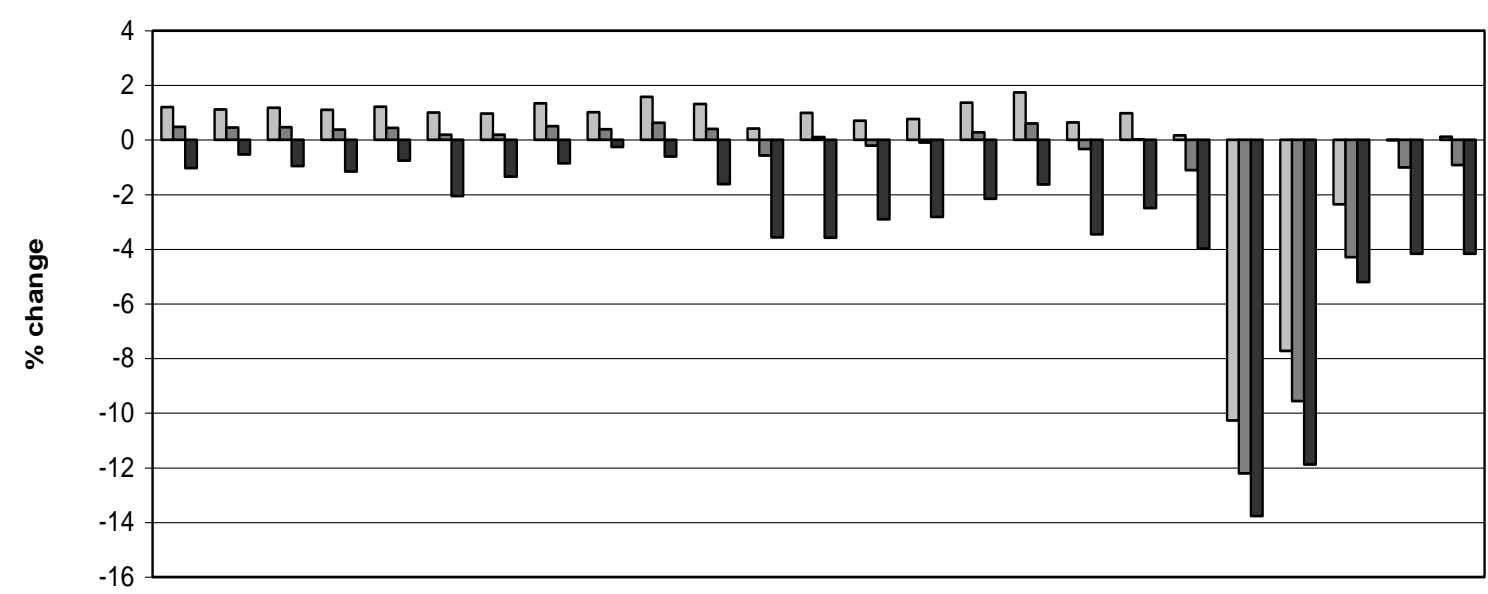

口Short-run

Medium-run

口Long-run

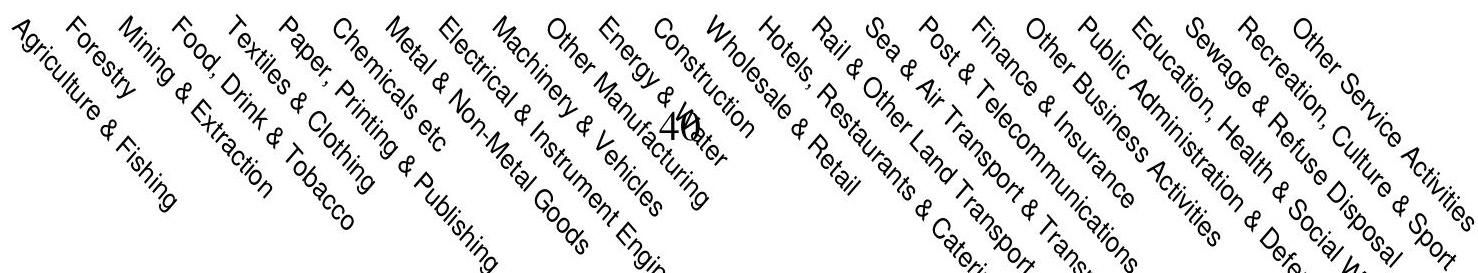


